\section{Impact of Overseeding Bermudagrass with Various Amounts of Perennial Ryegrass for Winter Putting Turf}

\author{
A.R. Mazur ${ }^{1}$ and J.S. Rice ${ }^{1}$ \\ Department of Crop and Soil Environmental Science, Clemson University, \\ Clemson, SC 29634-0359
}

Additional index words. cool-season, Cynodon dactylon $\times$ C. transvaalensis, Lolium

perenne, warm season

\begin{abstract}
Research was conducted to determine the influence of the rate of seeding perennial ryegrass (Lolium perenne $L$.) over bermudagrass [Cynodon dactylon (L.) Pers $x$ C. transvaalensis Burtt-Davy] on both the establishment of the ryegrass and the quality of bermudagrass golf greens. Increasing seeding rate from 90 to $180 \mathrm{~g} \cdot \mathrm{m}^{-2}$ resulted in more rapid establishment and a linear increase in turf quality. Turf density, as measured by leaf number, displayed linear and quadratic responses to seeding rates, with higher rates producing the greatest leaf numbers. Leaf width declined linearly with seeding rate, suggesting higher putting quality, as did tillers per plant. Spring transition to bermudagrass was slowed at high $\left(150-180 \mathrm{~g} \cdot \mathrm{m}^{-2}\right)$ seeding rates, with significantly more ryegrass present in late May. Emergence and growth of bermudagrass were suppressed longer at the higher overseeding rates. We conclude that the choice of seeding rate for ryegrass is a compromise between rapid development of, and maintenance of, quality turf vs. early smooth transition to bermudagrass in the spring.
\end{abstract}

Hybrid bermudagrass greens in the southern United States are usually overseeded in the fall with perennial ryegrass or other coolseason grasses to provide green color, a uniform surface, and tolerance to wear while the bermudagrass is dormant. Perhaps the greatest problem with overseeding is the transition to bermudagrass in the spring. Ideally, this should occur gradually, so that dormant bermudagrass is never visible. If the ryegrass dies abruptly, bermudagrass will require time to replace it. If the ryegrass lives too long, the bermudagrass will be slower to develop and take longer to recover. The ideal overseeding would rapidly establish a high-quality turf, maintain turf quality throughout the dormant period, and provide a smooth transition back to bermudagrass in the spring. Major problems are associated with loss of durability and aesthetics during fall and spring transitions. Establishment of ryegrass is most successful when soil tem-

Received for publication 24 Aug. 1998. Accepted for publication $19 \mathrm{Jan}$. 1999. Technical contribution No. 3151 of the South Carolina Agricultural Experiment Station, Clemson Univ., Clemson. The cost of publishing this paper was defrayed in part by the payment of page charges. Under postal regulations, this paper therefore must be hereby marked advertisement solely to indicate this fact.

${ }^{1}$ Professor. peratures are 22 to $26^{\circ} \mathrm{C}$ at a $10.2-\mathrm{cm}$ depth (Batten et al., 1980; Beard, 1988), which minimizes competition from bermudagrass and reduces likelihood of disease on ryegrass. Ryegrass germination is apparently optimal in that temperature range.

Seedbed preparation affects overseeding establishment, and stand failures may result at any seeding rate if preparation is not performed at the right time (Gill et al., 1967; Ward et al., 1974). Thatch removal and aeration with topdressing are most effective if performed 4 to 6 weeks prior to overseeding (Schimdt, 1970; Ward et al., 1974). Vertical mowing just prior to overseeding reduces competition from bermudagrass and removes thatch with a resulting improvement in seedling stands (Duble, 1978; Gill et al., 1967). Perennial ryegrass seeding rates of 150 to $200 \mathrm{~g} \cdot \mathrm{m}^{-2}$ are common (Duble, 1978; Schmidt, 1970; Ward et al., 1974), but rates of $100 \mathrm{~g} \cdot \mathrm{m}^{-2}$ or less have been recommended to reduce costs and allow more rapid transition to bermudagrass in the spring (Nutter, 1973). Duble (1978) reported more tiller formation, stronger plants, delayed transition, and an abrupt loss of ryegrass with an unacceptable playing surface at low seeding rates. Mazur (1987) reported that core aeration, vertical mowing, and topdressing had no positive influence on spring transition to bermudagrass. Herbicides and plant growth regulators speed spring transition to bermudagrass (Johnson, 1994; Mazur, 1988); in unacceptable playing surfaces. This study was initiated to determine the effects of overseeding rates of perennial ryegrass on fall transition to ryegrass, maintenance of turf quality, and spring transition to bermudagrass on a golf putting green. however, injury to perennial ryegrass resulted
Separate experiments were conducted in 1987-88 and 1988-89 on a 'Tifgreen' bermudagrass putting green mowed daily at $0.6 \mathrm{~cm}$ with normal cultural practices. The green had a $70 \%$ sand and $30 \%$ pine bark (v/v) root-zone medium. Applications of $5 \mathrm{~g} \cdot \mathrm{m}^{-2} \mathrm{~N}$, $2.2 \mathrm{~g} \cdot \mathrm{m}^{-2} \mathrm{P}$, and $4.2 \mathrm{~g} \cdot \mathrm{m}^{-2} \mathrm{~K}$ from urea $(45 \%$ $\mathrm{N})$, superphosphate $(8 \% \mathrm{P})$, and potassium sulfate $(50 \% \mathrm{~K})$, respectively, were made in September of each year. Isobutylidene diurea was applied monthly to supply $5 \mathrm{~g} \cdot \mathrm{m}^{-2} \mathrm{~N}$ from October to May each year. One week prior to overseeding, the area was vertically mowed in two directions with 1-mm-thick blades spaced at $1.27 \mathrm{~cm}$ and set to penetrate $2 \mathrm{~mm}$ into the soil. 'Gator' perennial ryegrass was overseeded at $90,120,150$, and $180 \mathrm{~g} \cdot \mathrm{m}^{-2}$ on 2 Oct. 1987 and 7 Oct. 1988. Immediately after seeding, plots were topdressed with washed sand at 1.8 $\mathrm{kg} \cdot \mathrm{m}^{-2}$. Overseeding treatments were arranged in a randomized block design with four replications. Plot size was $2.3 \times 2.3 \mathrm{~m}$. The plots were mowed for 2 weeks at a cutting height of $1.3 \mathrm{~cm}$, which was gradually lowered to 0.6 $\mathrm{cm}$ by the first week in November. The height was maintained at $0.6 \mathrm{~cm}$ for the duration of the study. Irrigation was applied to maintain optimum growth of the ryegrass.

Visual estimates of turf quality were made biweekly in 1987-88 and approximately monthly in 1988-89. Biweekly leaf counts, as an estimate of turf density, were made on three $12.5-\mathrm{cm}^{2}$ areas of each plot. Tiller counts were made on 10 randomly selected plants per plot on four dates in 1988 and 1989 to estimate seeding rate effects on plant size. In 1988-89, leaf widths were measured for 15 random plants per plot on five dates to estimate texture of the putting surface. Analysis of variance for each trait-year combination was performed as a split-plot in time with date as the sub-plot. Orthogonal comparisons were used to determine the response of seeding rates, dates of observation, and their interactions.

\section{Results and Discussion}

Turf quality increased linearly with increasing seeding rate ( Table 1). The 150 and $180 \mathrm{~g} \cdot \mathrm{m}^{-2}$ rates produced high-quality turf more rapidly than did the lower rates; the turf reached quality ratings of 8.0 and 8.9 , respectively, in $<30 \mathrm{~d}$, whereas the $120 \mathrm{~g} \cdot \mathrm{m}^{-2}$ rate required $60 \mathrm{~d}$ and the $90 \mathrm{~g} \cdot \mathrm{m}^{-2} 120 \mathrm{~d}$ to reach the minimal acceptable quality rating of 7.0. After $120 \mathrm{~d}$, quality consistently increased with increasing seeding rate. The results suggest that 150 or $180 \mathrm{~g} \cdot \mathrm{m}^{-2}$ are required to achieve rapid establishment of high-quality turf.

Leaf counts (an objective measure of turf density) displayed significant linear and quadratic responses to seeding rates in both years (Table 2), and seeding rate $\times$ date interaction was significant. Linear effects accounted for the majority of the variation in leaf number, and the increases in leaf number as seeding rate increased were larger during December and January. The incremental increases in leaf 
Table 1. Effect of seeding rate on turf quality ratings $\mathrm{s}^{\mathrm{z}}$ of perennial ryegrass on an overseeded bermudagrass putting green.

\begin{tabular}{|c|c|c|c|c|c|c|}
\hline $\begin{array}{l}\text { Seeding } \\
\text { rate } \\
\left(\mathrm{g} \cdot \mathrm{m}^{-2}\right) \\
\end{array}$ & & & Date of rati & & & \\
\hline \multicolumn{7}{|c|}{ 1987-88 } \\
\hline & 29 Oct. & 8 Nov. & 13 Nov. & 19 Nov. & 3 Dec. & 17 Dec. \\
\hline 90 & 6.2 & 5.6 & 6.1 & 6.0 & 6.9 & 6.2 \\
\hline 120 & 7.2 & 6.6 & 6.8 & 7.0 & 7.5 & 7.1 \\
\hline 150 & 8.0 & 8.0 & 7.9 & 8.1 & 8.2 & 8.1 \\
\hline 180 & 8.9 & 9.0 & 8.8 & 8.9 & 8.9 & 8.9 \\
\hline Linear & $* *$ & $* *$ & $* *$ & $* *$ & $* *$ & $* *$ \\
\hline Quadratic & NS & NS & NS & NS & NS & NS \\
\hline Cubic & NS & NS & NS & NS & NS & NS \\
\hline & 5 Jan. & 18 Jan. & 5 Feb. & $18 \mathrm{Feb}$. & 3 Mar. & $11 \mathrm{Mar}$. \\
\hline 90 & 6.1 & 7.0 & 7.1 & 6.9 & 5.9 & 8.0 \\
\hline 120 & 6.6 & 8.0 & 7.6 & 7.5 & 6.9 & 8.1 \\
\hline 150 & 7.9 & 8.5 & 8.2 & 8.2 & 7.4 & 8.5 \\
\hline 180 & 8.5 & 9.0 & 8.9 & 8.9 & 8.4 & 9.0 \\
\hline Linear & $* *$ & $* *$ & $* *$ & $* *$ & $* *$ & $* *$ \\
\hline Quadratic & NS & NS & NS & NS & NS & $*$ \\
\hline Cubic & NS & NS & NS & NS & NS & NS \\
\hline & 25 Mar. & 30 Mar. & 12 Apr. & 22 Apr. & 4 May & 27 May \\
\hline 90 & 7.1 & 7.4 & 8.0 & 8.0 & 8.2 & 7.2 \\
\hline 120 & 7.4 & 8.1 & 8.5 & 8.5 & 8.8 & 8.0 \\
\hline 150 & 7.5 & 8.1 & 8.5 & 8.5 & 8.9 & 8.0 \\
\hline 180 & 7.9 & 8.6 & 8.9 & 8.9 & 9.0 & 8.8 \\
\hline Linear & $* *$ & $* *$ & $* *$ & $* *$ & $* *$ & $* *$ \\
\hline Quadratic & NS & NS & NS & NS & NS & NS \\
\hline Cubic & NS & $*$ & $* *$ & $* *$ & NS & $*$ \\
\hline \multicolumn{7}{|c|}{$1988-89$} \\
\hline & 28 Oct. & 18 Nov. & 9 Dec. & & & \\
\hline 90 & 5.6 & 6.8 & 6.4 & & & \\
\hline 120 & 7.4 & 7.8 & 7.2 & & & \\
\hline 150 & 8.2 & 8.5 & 7.8 & & & \\
\hline 180 & 8.9 & 8.8 & 8.5 & & & \\
\hline Linear & $* *$ & $* *$ & $* *$ & & & \\
\hline Quadratic & $* *$ & NS & NS & & & \\
\hline \multirow[t]{2}{*}{ Cubic } & NS & NS & NS & & & \\
\hline & 6 Jan. & 8 Feb. & $21 \mathrm{Feb}$. & 17 Mar. & $21 \mathrm{Apr}$. & 24 May. \\
\hline 90 & 6.5 & 6.8 & 7.9 & 8.2 & 8.8 & 7.9 \\
\hline 120 & 7.4 & 7.4 & 8.4 & 8.2 & 8.2 & 7.8 \\
\hline 150 & 8.5 & 8.1 & 8.5 & 8.5 & 8.1 & 8.1 \\
\hline 180 & 8.5 & 8.8 & 9.0 & 8.6 & 7.6 & 8.4 \\
\hline Linear & $* *$ & $* *$ & $* *$ & NS & $*$ & $* *$ \\
\hline Quadratic & NS & NS & NS & NS & NS & NS \\
\hline Cubic & NS & NS & NS & NS & NS & NS \\
\hline
\end{tabular}

${ }^{\mathrm{z}}$ Visual estimates based on color, growth, and stand on a scale of 1 to 9 , where $1=$ completely brown and $9=$ no discoloration with uniform stand density and growth.

ss, * ** Nonsignificant or significant at $P \leq 0.05$ or 0.01 , respectively.
Table 2. Effect of seeding rate on mean leaf counts (number $/ \mathrm{cm}^{2}$ ) of perennial ryegrass on an overseeded bermudagrass putting green.

\begin{tabular}{|c|c|c|c|c|c|c|c|}
\hline $\begin{array}{l}\text { Seeding } \\
\text { rate } \\
\left(\mathrm{g} . \mathrm{m}^{-2}\right) \\
\end{array}$ & & & Date of & rating & & & \\
\hline \multicolumn{8}{|c|}{ Fall 1987} \\
\hline & 23 Oct. & 9 Nov. & 20 Nov. & 4 Dec. & 17 Dec. & & \\
\hline 90 & 1.8 & 2.9 & 3.6 & 3.6 & 4.0 & & \\
\hline 120 & 2.4 & 3.4 & 4.2 & 4.0 & 4.9 & & \\
\hline 150 & 2.9 & 4.1 & 4.8 & 4.5 & 5.6 & & \\
\hline 180 & 3.3 & 4.3 & 5.2 & 5.7 & 6.3 & & \\
\hline Linear & $* *$ & $* *$ & $* *$ & $* *$ & $* *$ & & \\
\hline Quadratic & NS & NS & NS & $* *$ & NS & & \\
\hline Cubic & NS & $*$ & NS & NS & NS & & \\
\hline \multicolumn{8}{|c|}{ Winter and Spring 1988} \\
\hline & $20 \mathrm{Jan}$. & 5 Feb. & 17 Feb. & 1 Mar. & 22 Mar. & 7 Apr. & \\
\hline 90 & 4.2 & 4.4 & 5.2 & 4.9 & 5.6 & 4.4 & \\
\hline 120 & 5.0 & 4.8 & 5.9 & 5.3 & 5.8 & 4.8 & \\
\hline 150 & 5.4 & 5.2 & 6.3 & 5.8 & 6.3 & 5.3 & \\
\hline 180 & 6.0 & 6.3 & 6.9 & 6.8 & 6.8 & 6.1 & \\
\hline Linear & $* *$ & $* *$ & $* *$ & $* *$ & $* *$ & $* *$ & \\
\hline Quadratic & NS & $* *$ & NS & NS & NS & NS & \\
\hline Cubic & NS & NS & NS & NS & NS & NS & \\
\hline \multicolumn{8}{|c|}{ Fall 1988} \\
\hline & 2 Nov. & 14 Nov. & 1 Dec. & 14 Dec. & & & \\
\hline 90 & 2.8 & 4.2 & 4.2 & 4.6 & & & \\
\hline 120 & 3.6 & 4.6 & 4.7 & 5.0 & & & \\
\hline 150 & 4.5 & 5.3 & 5.4 & 5.8 & & & \\
\hline 180 & 5.2 & 5.7 & 6.1 & 6.5 & & & \\
\hline Linear & $* *$ & $* *$ & $* *$ & $* *$ & & & \\
\hline Quadratic & NS & NS & NS & $*$ & & & \\
\hline Cubic & NS & NS & NS & NS & & & \\
\hline \multicolumn{8}{|c|}{ Winter and Spring 1989} \\
\hline & 16 Jan. & 30 Jan. & 22 Feb. & 13 Mar. & 27 Mar. & 10 Apr. & 24 Apr. \\
\hline 90 & 4.9 & 5.7 & 6.8 & 6.4 & 6.5 & 5.6 & 3.7 \\
\hline 120 & 5.6 & 6.4 & 7.3 & 7.0 & 7.1 & 6.6 & 3.8 \\
\hline 150 & 6.3 & 7.1 & 7.8 & 7.7 & 7.7 & 7.2 & 5.0 \\
\hline 180 & 7.5 & 8.0 & 9.2 & 8.8 & 8.5 & 7.5 & 5.4 \\
\hline Linear & $* *$ & $* *$ & $* *$ & $* *$ & $* *$ & $* *$ & $* *$ \\
\hline Quadratic & NS & NS & $* *$ & NS & NS & NS & NS \\
\hline Cubic & NS & NS & NS & NS & NS & NS & $*$ \\
\hline
\end{tabular}

ss, ${ }^{, * *}$ Nonsignificant or significant at $P \leq 0.05$ or 0.01 , respectively. numbers and, therefore, turf density, were larger at the higher seeding rates. Turf density was thus higher at higher seeding rates and the effect was accentuated at the two highest rates.

Leaf widths (an objective measure of texture) were measured in 1988-89. Leaf widths decreased as seeding rates increased, with no interaction with date (Table 3). The finest texture occurred at the highest seeding rates.

Since tiller number was counted on 10 plants per sample and the data were divided into single- and multiple-tiller plants (plants with one stem and plants with more than one stem), the analysis of variance is identical for the two traits. Tillering rate decreased significantly with increasing seeding rate (Table 3 ). The greater tillering rate of the low seeding rates would decrease potential differences in density, quality, and leaf width.

The percentage of green bermudagrass in the turf displayed significant linear, quadratic, cubic, and linear $\times$ date effects in 1987-88 (Table 4), but only linear effects were detected in 1988-89. At the time of the first rating on 4 May 1988, bermudagrass had largely displaced ryegrass at the lower seeding rates, especially at $90 \mathrm{~g} \cdot \mathrm{m}^{-2}$. The turf at $180 \mathrm{~g} \cdot \mathrm{cm}^{-2}$ was less than half bermudagrass and by late May was still almost 30\% ryegrass. Earlier ratings in 1989 showed a somewhat clearer transition, with $\approx 55 \%$ bermudagrass by late May at the 180 $\mathrm{g} \cdot \mathrm{m}^{-2}$ rate. Emergence of bermudagrass was delayed as seeding rate increased. This response is opposite to that reported by Duble (1978). Apparently, the higher seeding rates did not result in weakened perennial ryegrass plants that died sooner. Bermudagrass suppression thus lasted longer at the higher seeding rates of perennial ryegrass.

Increasing perennial ryegrass seeding rates from 90 to $180 \mathrm{~g} \cdot \mathrm{m}^{-2}$ resulted in higher turf quality sooner, with higher density and finer leaf texture. The higher seeding rates produced turf of better quality throughout the ryegrass growing season. In contrast, lower seeding rates resulted in plants with more tillers, and earlier bermudagrass emergence in the spring. The choice of seeding rate is thus a compromise between turf quality and spring transition. If higher turf quality is desired, then the higher seeding rates should be used. The $150 \mathrm{~g} \cdot \mathrm{m}^{-2}$ rate may be an appropriate choice, but delays transition to bermudagrass in the spring. 
Table 3. Effects of seeding rate of perennial ryegrass on mean leaf width of seedlings, and on number of plants with a single tiller following overseeding on a bermudagrass putting green.

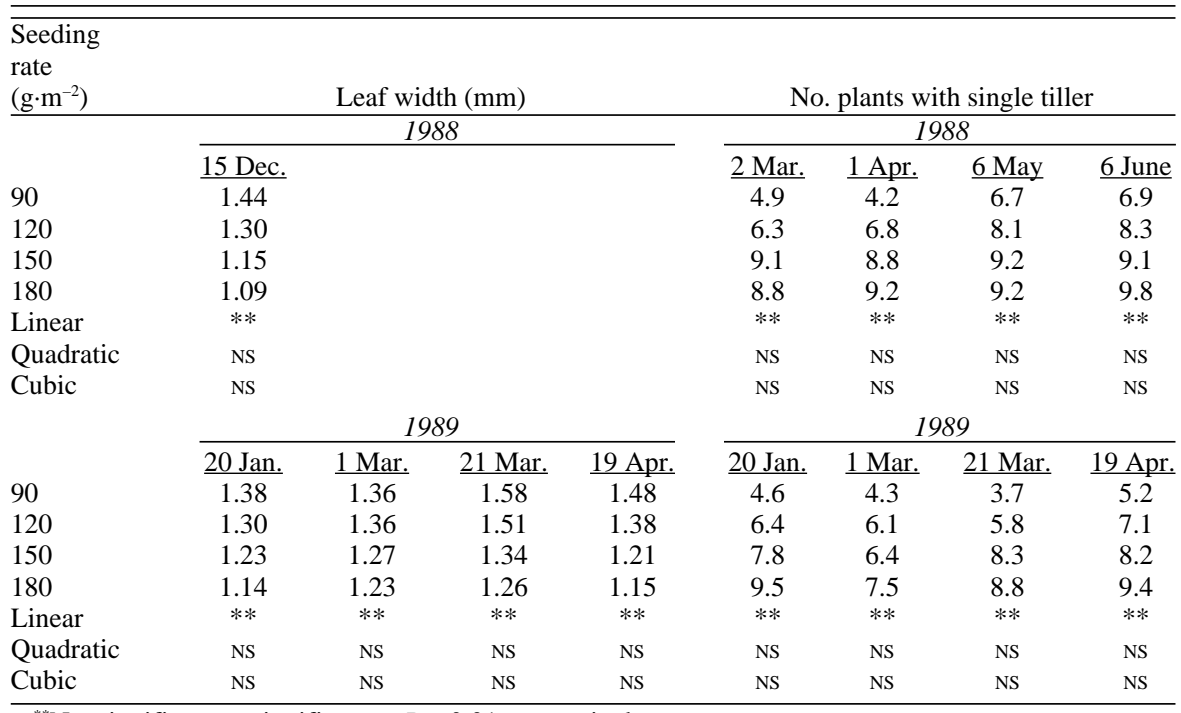

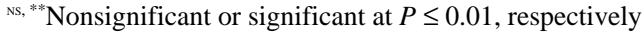

\section{Literature Cited}

Batten, S., J.B. Beard, and D. Johns. 1980. Monitoring soil temperature to determine overseeding rates. Grounds Maint. 15(9):42-48.

Beard, J.B. and W.G. Menn. 1988. The Texas system of winter overseeding. Grounds Maint. 23(9):14.

Duble, R.L. 1978. Overseeding bermudagrass turf. Southern Golf 9(4):20-23

Gill, W.J., W.R. Thompson, Jr., and C.Y. Ward. 1967. Species and methods for overseeding bermudagrass greens. Golf Superintendent
$35: 10-17$

Johnson, B.J. 1994. Influence of diclofop and dithiopyr on spring transition of a bermudagrass (Cynodon dactylon) green overseeded with perennial ryegrass (Lolium perenne). Weed Tech. 8:207-211.

Mazur, A.R. 1988. Influence of plant growth regulators on overseeded bermudagrass putting green turf. J. Amer. Soc. Hort. Sci. 113:367-373.

Mazur, A.R. and D.F. Wagner. 1987. Influence of aeration, topdressing, and vertical mowing on overseeded bermudagrass putting green turf. HortScience 22:1276-1278
Table 4. Bermudagrass spring transition (\%) at four seeding rates of perennial ryegrass on an overseeded putting green.

\begin{tabular}{|c|c|c|c|c|}
\hline \multirow{3}{*}{$\begin{array}{l}\text { Seeding } \\
\text { rate } \\
\left(\mathrm{g} \cdot \mathrm{m}^{-2}\right)\end{array}$} & \multicolumn{4}{|c|}{ Date of rating } \\
\hline & \multicolumn{2}{|c|}{1988} & \multicolumn{2}{|c|}{1989} \\
\hline & 4 May & 25 May & $21 \mathrm{Apr}$ & $19 \mathrm{Ma}$ \\
\hline 90 & 87.5 & 94.5 & 43.8 & 88.8 \\
\hline 120 & 72.5 & 85.8 & 33.8 & 67.5 \\
\hline 150 & 72.5 & 83.8 & 20.0 & 63.5 \\
\hline 180 & 40.4 & 71.2 & 19.2 & 54.8 \\
\hline Linear & $* *$ & $* *$ & $* *$ & $* *$ \\
\hline Quadratic & $* *$ & NS & NS & NS \\
\hline Cubic & $* *$ & $*$ & NS & NS \\
\hline
\end{tabular}

ss, ${ }^{*},{ }^{* *}$ Nonsignificant or significant at $P \leq 0.05$ or 0.01 , respectively.
Nutter, G.C. 1973. Overseeding wintergrass greens. So. Golf Course Operations 4(2):18.

Schimdt, R.E. 1970. Overseeding cool-season turfgrass on dormant bermudagrass for winter turf, p. 124-129. In: J.B. Beard (ed.). Proc. First Intl. Turfgrass Conf. Sports Turf Res. Inst,, Bingley, England.

Ward, C.Y., E.L. McWhirter, and W.R. Thompson, Jr. 1974. Evaluation of cool-season turf species and planting techniques for overseeding bermudagrass golf greens, p. 480-495. In: E.C. Roberts (ed.). Proc. Second Turfgrass Res. Conf., Amer. Soc. Agron., Madison, Wis. 